\title{
La Importancia del Cambio Político en México y su Influencia en el Gobierno y la Administración Pública
}

\author{
Ricardo Uvalle Berrones \\ Universidad Nacional Autónoma de México
}

\begin{abstract}
Resumen: El presente texto es una reflexión sobre el impacto de los cambios políticos en el gobierno y la administración pública. La nueva dimensión que han cobrado los procesos electorales en México, ha ocasionado un reordenamiento democrático en el país, que implica nuevos retos para la investigación y un replanteamiento de las estructuras y las formas de gobernar para vivir en la democracia que deseamos.

Abstract: The main focus of this paper is to reflect about the impact of the political changes in government and public administration. As a consequence of the new dimension that has reached the electoral process in Mexico, it has been a new democratic restructure, wich implicates new challenges for research and to reconsider the main government structures and the way of ruling the country for living at the democracy that we wish.
\end{abstract}

\section{Introducción}

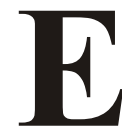

1 objetivo del presente trabajo es reflexionar sobre los nuevos tiempos que el país vive en el ámbito de la política. Se han generado procesos que apuntan por un comportamiento distinto al que se ha vivido desde la etapa posrevolucionaria. En la actualidad, se suceden reacomodos en las estructuras del poder, mismos que configuran un escenario más competitivo entre los diversos actores políticos y sociales.

El México bronco, el de las instituciones, las reformas y la continuidad institucional, se condensa en una realidad de contrastes, contradicciones y transformaciones que constituyen el motor del cambio histórico que hoy día influye en la vida compleja de las instituciones públicas. En esta lógica prevalecen el cambio y la continuidad, los cuales se encaminan a favorecer las bases de una estabilidad política, sin desvincularse del imperativo de gobernabilidad democrática.

México es un mosaico cultural, social y político, lo cual significa que los procesos del poder son fruto de una realidad disímbola que, con 
su dinamismo, expresa cómo los diversos proyectos para construir y fortalecer las instituciones, tienen como ámbito una suma de intereses, valores, costumbres, símbolos y medios que los diversos actores definen para incursionar por la senda de la lucha política.

De este modo, las elecciones del 6 de julio de 1997 se inscriben en la dinámica y objetivos del cambio pacífico. Son consecuentes con los valores e instituciones de los sistemas democráticos y pueden fungir como detonador de las transformaciones institucionales. Son punto de partida para situar los cambios futuros del país, y en ningún momento constituyen una tendencia apocalíptica o destructiva que es propia de las geometrías políticas. Son oportunidad para transitar por las vías de la tolerancia, con el propósito de que los intereses y fuerzas que compiten por la conquista y retención del poder, tengan los espacios institucionales que garantizan que las contiendas políticas no se traduzcan en el aniquilamiento de los opuestos.

Las elecciones se inscriben en la dinámica de cambios que se viven con intensidad desde los años ochenta, y que en la actualidad provocan un reacomodo en las cuotas de poder. México ha ingresado a una nueva fase de la correlación de fuerzas, lo cual implica ampliar los equilibrios institucionales que, sin duda, tendrán influencia en el funcionamiento del gobierno y la administración pública, a partir de la nueva relación de pesos y contrapesos dada entre el Ejecutivo federal y la Cámara de Diputados.

La reflexión sobre los acontecimientos políticos del segundo semestre de 1997, es oportunidad para analizar el rumbo del gobierno y la administración pública en una situación en que los límites del presidencialismo, que no del régimen presidencial, han tocado fondo; en que la Cámara de Diputados, después de 80 años de vida constitucional, no es controlada por el partido en el gobierno; en que las oposiciones jugarán a construir alianzas pragmáticas que no implican desacuerdo insuperable con la fracción del partido gobernante ; en suma, se vislumbra una situación política novedosa, tensa y convergente no por sí misma, sino como fruto de acuerdos negociados y de contratiempos superados.

\section{Sustento teórico}

Los procesos electorales son oportunidad para encauzar la renovación y la alternancia en el poder. Son un momento en la vida política que 
recrea con sentido positivo la relación entre gobernantes y gobernados. Las elecciones son testimonio de cómo la libertad y la democracia se constituyen en pilares centrales de la sociedad moderna.

Por la libertad, los ciudadanos ejercen el sufragio universal y deciden cómo se debe gobernar. Por la democracia (Rawls, 1996: 208), los ciudadanos deciden quién ha de gobernar. Tanto la libertad como la democracia son el binomio que permite a la sociedad moderna acceder a la renovación y consolidación de las prácticas del poder, teniendo como referente tanto las instituciones como los procesos de institucionalidad. Una sociedad madura y consolidada por las ventajas de la democracia se constituye en un cuerpo dinámico, cuya capacidad de organización, movilización y proyección es constante. En este sentido, una sociedad activa con orientación democrática no tiene punto de reposo y se manifiesta en una diversidad de ángulos que dan cuenta de su energía ciudadana y de las iniciativas que puede formular en favor de los asuntos públicos.

Las elecciones tienen dos facetas que las constituyen en parte fundamental para acrecentar el contrato social, a saber: legalidad y legitimidad. La legalidad se relaciona de manera puntual con las condiciones, protagonistas, instituciones y reglas que permiten que el poder sea articulado como un sistema de prácticas formales, convenidas entre los actores políticos. La legitimidad alude al reconocimiento, aceptación y prestigio de quienes han triunfado (Arbós y Giner, 1996: 52) en la contienda político- electoral, lo cual significa que el consenso obtenido tiene alcance significativo, que se traduce en un importante capital político.

Ejercer el sufragio universal es un acto que refleja voluntad, preferencias, elección y tipos de recompensa en favor de un candidato o de otro. Elegir es decidir quién debe gobernar, para qué y qué medios deben aprovecharse para responder a las expectativas de los ciudadanos. Elegir significa no incurrir en la autoexclusión y tomar posición en relación con una o varias ofertas políticas que se formulan por los actores en competencia. Elegir significa romper la pasividad que nace del escepticismo, la desconfianza y la duda que se genera cuando los resultados y procesos no son dignos de confianza. Elegir es decidir ante ofertas en competencia, entre actores que aspiran a ganar el voto ciudadano y entre organizaciones partidistas que luchan por conquistar el poder público. 
En este sentido, los procesos electorales son pieza esencial de la cadena que se mueve en dirección a la democracia participativa y representativa. En tiempos de apertura y democratización, las elecciones posibilitan que la civilidad de la contienda sea un elemento básico del prestigio de las instituciones y que la institucionalidad sea un sistema que conjugue democracia y gobernabilidad (Arbós y Giner, 1996: 13).

De este modo, la política competitiva es el indicador más fehaciente de cómo los actores del poder se interesan en la organización, ejercicio y competencia del mismo. La política competitiva es fruto del interés que los actores tienen en la contienda electoral. Revela madurez cívica para aceptar que en la lucha por el poder no hay triunfos definitivos o concluyentes, ni victorias de vida o muerte. Los triunfos en política, más en la competitiva, son transitorios. No hay pues equilibrios estáticos ni trazos lineales para retenerlo invariablemente. Los movimientos del poder son aleatorios e inciertos, lo cual implica que su lucha sea a través de procesos intensos, complejos y cambiantes

En una visión de la democracia moderna, la política competitiva es un gran vehículo para movilizar grupos, formular ofertas, ganar consensos, asegurar votos y encaminarse por la senda de la lucha institucional. La política competitiva es producto de las condiciones que una sociedad es capaz de crear para organizarse en el ámbito de un sistema de instituciones y revela cómo éstas deben ser creativas, flexibles y eficaces para asegurar que la conquista del poder sea objeto de racionalidad pública.

Recordando a Weber, puede decirse que quien hace política "aspira al poder como medio para conseguir fines idealistas o egoístas". En efecto, la política y el poder son el binomio que incentiva a los ciudadanos para organizarse y definir estrategias de lucha partidista.

La política (Peschard, 1996: 9) como actividad, permite movilizar recursos, grupos y organizaciones para conquistar el poder. Situada en la trama de los apoyos a negociar, la política es un medio para construir alianzas que posibilitan sumar actores y articular intereses para acceder a los centros de la decisión suprema.

El poder, por su parte, es un conjunto de hechos inobjetables que testimonian cómo llevar a cabo la coordinación imperativa de los demás y es un camino para cumplir proyectos de vida, de acuerdo con valores, ideología y medios de acción. El poder se basa en la política y 
la utiliza para conseguir resultados eficaces, cuando se tiene el mando público y político de un país.

Lo importante de la política y el poder es que deben aplicarse con inventiva, teniendo como referencia que el respeto entre ganadores y no ganadores es fundamental para que las instituciones no sean quebrantadas con prácticas fundamentalistas o posturas excluyentes. El mayor riesgo de quebranto (Przeworski, 1991: 10) institucional se da cuando los actores violentan las reglas de la competencia o bien, cuando una vez que triunfan, incurren en prácticas que fermentan la atomización de la sociedad, la fragmentación del tejido político, la pérdida del espíritu de lo público y la sobrevaloración de las relaciones clientelares.

Cuando la política competitiva es objeto de institucionalidad, significa que los conflictos se abordan e ingresan a procesos y fases que denotan diversos tipos de solución. En la democracia, la institucionalidad de los conflictos es factor insoslayable para evitar que la sociedad se consuma en el enfrentamiento estéril de los actores del poder. Cuando los conflictos desbordan y rebasan a las instituciones, se pierde la oportunidad de que las reglas sean la base para moderar desacuerdos, desactivar posturas extremistas y crear condiciones favorables para el desarrollo de las contiendas políticas.

La institucionalidad (O'Donell, 1996: 235) entendida como un conjunto de reglas convenidas, vigentes y difundidas, permite que la sociedad ingrese a fórmulas de asociación que coadyuven a una mejor articulación de los intereses en competencia. En este caso, la institucionalidad democrática es un medio que contribuye a evitar que las diferencias no deriven en antagonismos irreductibles. Garantiza a la vez, que los sistemas de transacción contribuyan a estructurar arreglos y compensaciones, reconociendo que el juego del poder se desenvuelva con apego a reglas puntuales y eficaces.

Las ventajas de la institucionalidad democrática se manifiestan en que tiene los medios y recursos para absorber el universo amplio, diverso y complejo del pluralismo político y lo reconoce como pieza importante del sistema democrático de vida, el cual es consubstancial a la sociedad moderna. Esto significa que las instituciones democráticas dan cabida a mayorías y minorías, ordenan expectativas, modulan rivalidades y permiten, en razón de su esencia, que los triunfadores de hoy, a lo mejor no son los de mañana; o bien, quienes hoy no han 
ganado, en el futuro lo consigan. Las instituciones democráticas garantizan que la lucha por el poder se apoye en reglas que propicien certidumbre en cuanto que los procesos de la misma, tengan las instancias, decisiones, procedimientos y estructuras para organizar la competencia política, calificar los resultados, dirimir los conflictos y reconocer la legalidad de las contiendas.

Ésta es la ventaja de las instituciones democráticas a la cual debe agregarse que los incentivos para los actores políticos es una contribución en favor de las propias instituciones. Ganar o perder no son opciones concluyentes, sino acicate para que la competencia sea más intensa y continua. Recordando a Adam Pzreworski, la democracia es un sistema que se desarrolla en el ámbito de la "incertidumbre institucionalizada".

Por eso, la democracia política (Bobbio, 1996: 24) en cuanto sistema de procedimientos susceptibles de corrección, permite que los conflictos tengan sitios en la institucionalidad progresiva; que la competencia sea visualizada en términos de adversarios; la alternancia en el poder sea periódica, ordenada y con reglas diáfanas para que el ejercicio de la función pública sea motivo de rendición de cuentas y que las actividades del gobierno sean objeto de mejoramiento continuo, tomando en cuenta las ventajas de la evaluación, dado que las organizaciones ciudadanas pueden y deben formular opiniones que permitan focalizar los aspectos relevantes de la compleja acción del gobierno.

Por otra parte y como método de gobierno, la democracia se asocia con la expresión civilizada de los opuestos, la formulación de acuerdos que pueden ajustarse y replantearse en razón de expectativas, demandas, el comportamiento de los actores y la rearticulación entre el gobierno y la sociedad. En la democracia, los mejores valores de la convivencia humana tienen opción para traducirse de proyecto (Przeworski, 1997: 143) en realidad tangible. Por la democracia, los individuos y las organizaciones sociales acceden al debate público y al reconocimiento de las instancias clave para orientar los cursos de la vida colectiva.

En la democracia moderna, los gobiernos y las administraciones públicas desarrollan sus tareas con base en la separación y división de poderes. Son consideradas instituciones que regulan la vida social y política para favorecer el cumplimiento de objetivos que sean 
productivos, emprendedores y visionarios. Además, se enlazan con base en los sistemas de pesos y contrapesos para evitar que el poder se concentre y consiga bloquear los movimientos ciudadanos que emergen con la participación de los actores políticos.

\section{Reordenamiento democrático en México}

México ha vivido, en los últimos 27 años, procesos que apuntan por un mayor auge de las prácticas que se orientan por la senda de la democratización. Los vínculos Estado-sociedad son objeto de rearticulación, lo cual provoca que las estructuras del poder pierdan su carácter de estatua de sal. Es un hecho innegable la emergencia de nuevas fuerzas y energías ciudadanas, mismas que influyen en el reacomodo de la vida pública para que sea más abierta, competitiva e intensa. Existen nuevos grupos y demandas que ocupan un lugar significativo en el centro de los procesos del poder y ello constituye un cambio entre las realidades que en otros tiempos daban cuenta de un estatismo que adormecía la iniciativa de los ciudadanos y las que en la actualidad testimonian el reencuentro de los ciudadanos con sus organizaciones y el espacio de lo público.

Los intentos por desestatizar la sociedad y el mercado, cobran importante auge, dado que las capacidades individuales reclaman sitios que en otros tiempos les fueron saturados con más acción administrativa y estatal. De igual manera, los diques al corporativismo y al paternalismo (Fernández, 1997: 88), han aumentado debido a que la participación ciudadana se intensifica y provoca modificaciones sustanciales en las estructuras verticales del poder. En este caso, la voluntad de cambio y la resistencia al mismo, conforman situaciones contradictorias y tensas que deben gobernarse en términos de la institucionalidad democrática, evitando que las prácticas, costumbres y valores autoritarios reactiven su presencia en la vida política.

El autoritarismo del sistema político mexicano se ha sustentado en la concepción borbónica del poder, en el ejercicio unipersonal (Fernández, 1997: 84) de las decisiones, en los arreglos cupulares, en la exclusión de organizaciones y ciudadanos, en el incremento de la burocratización, en la ausencia de un sistema de pesos y contrapesos y en la falta de lo que es la rendición de las cuentas públicas.

El autoritarismo ha impedido que la democracia sea considerada como un gobierno de instituciones y ha favorecido hasta sus últimas 
consecuencias el gobierno de los hombres. El autoritarismo (Marván, 1997: 30) no reconoce las ventajas de las instituciones, sino que decide de acuerdo con el pragmatismo casuístico. Frena las iniciativas de los ciudadanos, desmoviliza las acciones de la sociedad y bloquea los propósitos de renovación y cambio democrático.

El autoritarismo es consustancial a los valores faraónicos del Estado, a la politización innecesaria de la economía, a la promesa de los paraísos incumplidos y a los objetivos que evitan que la sociedad pueda desarrollarse de acuerdo con sus capacidades. No concibe a la sociedad sin la presencia abrumadora del Estado y finca en el uso discrecional de los recursos públicos, la efectividad de sus prácticas políticas. Para el autoritarismo no hay evaluación de capacidades que permitan determinar los límites fiscales, legales, organizativos y políticos del Estado. Por el contrario, erige al Estado en necesidad artificial para legitimar que el ejercicio del poder sea piramidal y centralizado.

Sin embargo, en política no hay realidades incambiables ni procesos inmutables. En ese sentido, el autoritarismo empieza a tocar fondo, debido a que los movimientos democratizadores que se gestan en la sociedad y que se organizan con mayor frecuencia, tienen vitalidad y ganan lugares estratégicos para impedir que el Estado majestuoso, litúrgico y providencial sobreviva en cuanto credo y sistema de prácticas gubernamentales y administrativas.

No más Estado innecesario y sí más vida social y ciudadana son proclamas que recorren el país para postular los valores del cambio continuo y democrático. No más Estado nodriza ni más administración pública sobredilatada (Aguilar, 1996: 26) son propósitos de una sociedad que toma conciencia del protagonismo que le corresponde como cuerpo activo, productivo y emprendedor. Las relaciones Estado-sociedad se han transformado hasta articularse en nuevas realidades que se caracterizan por la orientación hacia una economía de mercado, la liberalización de la vida política, la apertura del gobierno y los esfuerzos por impulsar los procesos de la descentralización política y administrativa.

De igual manera, la aplicación de políticas correctivas en materia de gasto público, deuda externa y déficit fiscal han tenido relevancia en la agenda del gobierno, pues constituyen medios para evitar una mayor asimetría entre la vida productiva de la sociedad y el Estado. Las 
políticas correctivas son un tipo de respuesta institucional para llevar a cabo el reordenamiento del Estado. Centran su atención en superar y evitar los desajustes estructurales del propio Estado y postulan la importancia de que sus tareas sean necesarias y por tanto, justificadas.

Las políticas correctivas son un medio de alcance temporal y su impacto es mayor cuando se postergan los ajustes del cambio estructural. Entonces, el tiempo de su necesidad tiende a prolongarse, debido a que los males públicos - déficit fiscal y endeudamiento interno y externo-, se vinculan negativamente con el ser de la sociedad, es decir, con su vida productiva, hasta afectarla con periodos de recesión, inflación crónica y estancamiento.

En esa medida, la aplicación de políticas correctivas afecta la médula de la tasa de impuestos, la cuantía de las inversiones privadas, la magnitud de los consumos, los niveles de empleo, el valor de lo salarios y los procesos de intercambio. Por eso, corregir los excesos del estatismo es un proceso que impacta a la sociedad, pero es condición necesaria para que el Estado elimine el crecimiento injustificado de sus áreas administrativas y burocráticas, las cuales necesitan del excedente económico para su operación y sostenimiento. Sin embargo, cuando el crecimiento administrativo del Estado se realiza dilapidando la riqueza material de la sociedad, sobreviene el efecto agudo de las políticas expansionistas que son financiadas aun con déficit fiscal (Elizondo, 1997: 12).

En la actualidad, el tránsito de una economía estatizada a una economía más pública forma parte de la premisa de que el Estado no debe realizar lo que corresponde y sabe hacer la sociedad. Cuando la sociedad tiene condiciones de desarrollo, significa que el Estado cumple su misión pública y social. Cuando la sociedad frena su desarrollo, significa que el estatismo diseña e implementa políticas que no son funcionales para la sociedad. Por tanto, es importante que el Estado lleve a cabo procesos que tengan por objeto mejorar sus rendimientos, evitando que las políticas que adopta sean consideradas como males públicos. En este sentido, la nueva relación de la sociedad con el Estado es un factor importante a considerar para ubicar el comportamiento político-electoral del país, dado que los reclamos en favor de que el espacio público sea reconocido como lugar de la sociedad y los ciudadanos, rompe con la conducta faraónica que lo invocaba como monopolio exclusivo del Estado. La desestatización 
del espacio público es consustancial al auge de los ciudadanos organizados, quienes a través de sus organizaciones, consiguen la apertura de estructuras de poder que antes tenían vedadas. Abrir las esferas de la decisión en el campo de la política, ha permitido incrementar la publicitación y ciudadanización del poder.

De acuerdo con lo expuesto, las elecciones del 6 de julio del año pasado se caracterizan como un proceso que condensa los elementos siguientes: 1) el fortalecimiento de la ciudadanización; en este caso, los partidos políticos propusieron a ciudadanos que no son militantes, para que sean miembros del Consejo General del Instituto Federal Electoral y de ese modo tengan un papel activo y corresponsable en la dirección, organización, administración e implementación de los asuntos electorales; 2) el reconocimiento de la oposición democrática, es decir, la que acepta las reglas institucionales; 3) el fortalecimiento del pluralismo competitivo; 4) la capacidad para atender y resolver conflictos poselectorales; 5) el cumplimiento y confianza en las reglas acordadas; 6) un reconocimiento más amplio a la oposición constitucionalizada; 7) un cambio significativo en la correlación de fuerzas de la Cámara de Diputados, ya que ninguna fuerza política tiene mayoría absoluta; 8) una expresión más amplia de la cultura cívica; 9) el ingreso a la etapa de mayores acuerdos para negociar posturas parlamentarias y 10) un nueva relación del Ejecutivo federal y la Cámara de Diputados.

Las elecciones federales han corroborado la voluntad del gobierno y los ciudadanos para que la lucha política tenga reglas de certidumbre en favor de la estabilidad y gobernabilidad. Son prueba de cómo la lucha por el poder transita de estructuras rígidas a flexibles, mismas que dan cauce a las diversas posiciones políticas. Así, la política de candilejas es reemplazada por las ventajas de la luz pública, la cual es producto de la acción organizada y coordinada de los ciudadanos y permite que las prácticas del poder sean objeto de mayor transparencia y de una más amplia y convincente rendición de cuentas. La publicitación de la política es consecuente con los postulados e instituciones de una sociedad que aspira a organizarse con estructuras abiertas y competitivas, para dejar atrás los sistemas rígidos y cerrados, los cuales, por definición, son opuestos a los que tienen naturaleza deliberativa y democrática. 
En este caso, y en lo fundamental, las conductas políticas reflejan la composición de un pluralismo más nutrido, de contendientes más interesados en aceptar las reglas de la competencia democrática y en tipos de participación que incrementan el interés en los asuntos de carácter común.

Sin duda, las elecciones son un acontecimiento importante para la vida nacional. Permiten ratificar desde el ángulo de la decisión ciudadana la opción que tiene para castigar o recompensar a los candidatos a ocupar cargos de elección popular. También permiten oxigenar las relaciones entre el gobierno y los ciudadanos, dado que lo nutrido de los sufragios emitidos, es prueba de que la convocatoria para ejercer el derecho a votar fue exitosa.

En este sentido, el mercado político-electoral fue dinámico y tanto las ofertas como las demandas políticas, tuvieron condiciones idóneas para difundirse y traducirse en preferencias que culminaron en el derecho a decidir quién debe gobernar. El mercado político - electoral es cada vez más relevante. Su reconocimiento como espacio de opciones, elecciones y decisiones es incuestionable. En él, los ciudadanos valoran la información que se genera, dado que permite afinar criterios y preferencias. Su dinamismo estimula que la competencia entre los partidos sea intensa y las distintas ofertas políticas que se formularon al público elector, han sido determinantes para comparar las ventajas de cada una.

Han sido las elecciones un paso más en favor del reordenamiento democrático del país. Dicho reordenamiento institucionaliza una nueva relación entre mayorías y minorías, entre consensos y oposición $\mathrm{y}$ reconoce por vez primera, que hay en el régimen político un nuevo sistema de balances y decisiones que articulan los ámbitos del poder Ejecutivo federal y la Cámara de Diputados. El reordenamiento democrático del país implica una situación en que la relación entre la Cámara de Diputados y el Ejecutivo federal tendrá que desarrollarse en condiciones que exigen más comunicación y cooperación entre ambos centros de poder.

No hay duda de que un poder legislativo activo, dinámico y celoso de las tareas de vigilancia y rendición de cuentas será más exigente con el gobierno y la administración pública, y el desempeño de éstos tendrá que vincular calidad, esmero, capacidad y resultados eficaces. El reordenamiento democrático es resultado de procesos de liberalización 
política (Loaeza, 1996: 174-175) y del impulso dado a la política de apertura. Se trata pues, de un reordenamiento deliberado, inducido y formalizado.

En todo proceso de reforma institucional se aceleran o retrasan los procesos de cambio. Ante las reformas, no es posible con-descecender con todos, pero sí es factible unir las fuerzas del cambio que, como fuerzas protagónicas, juegan un papel central para orientar los acontecimientos hacia horizontes distintos de los que se conocen. Las reformas, en cuanto tipo de cambio institucional, son procesos que se orientan hacia otros estadios y exigen, por tanto, que las fuerzas políticas asuman el riesgo que implica modificar estructuras, procesos y cuotas de poder.

Las reformas visionarias aspiran a crear un orden dinámico y democrático para dar cauce a más fuerzas ciudadanas. Reformar implica modificar, alterar, adaptar y revitalizar a sistemas políticos que, con el transcurso del tiempo y la complejidad de la lucha política, requieren habilitamiento creativo para que el juego del poder se desenvuelva en los terrenos de la institucionalidad democrática. Tanto en su curso como en su prueba final, las reformas son procesos de incertidumbre, dado que, al institucionalizar a otras fuerzas en competencia, se tiene como resultado una modificación significativa en la correlación de fuerzas. Esto no constituye una patología o situación excepcional. Es un riesgo que se asume cuando las exigencias democráticas se traducen en realidades ineluctables.

En el caso del 6 de julio, las elecciones conforman una realidad que modifica la correlación de fuerzas en favor de las oposiciones, sin que implique la eliminación de los adversarios, en este caso, de la fracción parlamentaria del Partido Revolucionario Institucional. Es una realidad política que da cuenta de cómo México transita de procesos autoritarios, estatizantes y corporativos a otros que recogen la voluntad de los ciudadanos y que se manifiesta en comportamientos electorales inéditos. Esta nueva realidad no se forma de manera súbita, sino que emerge con vitalidad desde finales de los sesenta, continúa en los setenta, en los ochenta se define como un tipo de insurgencia ciudadana y en los noventa tiene un papel decisivo para modificar con sentido democrático, el derecho a elegir otras opciones que reformulan la relación gobierno-sociedad. 
Desde una visión de la democracia moderna, el reordenamiento que México ha vivido es fruto de una acción ciudadana que incrementa su presencia de manera significativa en los procesos del poder. Es fruto de que la ciudadanía no desea trato de súbdito (Silva-Herzog, 1996: 19), sino que exige respeto a sus derechos para que no se los vuelvan a expropiar con políticas estatizantes que han tenido inspiración colonial, autoritaria y centralista.

Superar la noción de sociedad cerrada para transitar y llegar a lo mejor de la sociedad abierta, es una demanda ciudadana que se gesta y proyecta de acuerdo con los valores de una civitas revitalizada (Bell, 1996: 231). La importancia de la civitas se manifiesta como un caudal de preferencias y votos que han modificado el comportamiento político del país, para vincular los procesos de liberalización y transición (Ruiz, 1994: 125 y 133).

Desde el mirador de la democracia contemporánea, el reordenamiento político debe entenderse como una situación que exige capacidad de adaptación e inteligencia y que, en el caso de México, es el inicio de una etapa de mayor competencia política que implicará mejor destreza en la tarea de gobernar.

Para las oposiciones que han logrado triunfar, es indispensable que articulen con responsabilidad la lealtad institucional. La lealtad institucional es un valor primordial para evitar que el gobierno sea entendido como una entidad partidista. La lealtad institucional se acredita cuando el gobierno es puesto a salvo de las camarillas partidistas y es considerado como una institución común a todos los gobernados. La gobernación de la sociedad es efectiva cuando las reglas institucionales son el medio para preservar al propio gobierno y cuando los problemas públicos son atendidos sin visión ideologizada de grupo, clase o corporación. La lealtad institucional necesita de funcionarios al servicio de los ciudadanos y que de manera continua invoquen el interés público como referente innegociable de lo que significa el buen gobierno.

Cuando se gobierna, la lealtad partidista no debe suplantar a la lealtad institucional. Por el contrario, cuando se gobierna se debe atender e incluir a todos, es decir, a quienes votaron a favor y a quienes con su derecho ciudadano, votaron por opciones distintas a las triunfadoras. El gobierno de la democracia (Ruiz, 1994: 134) reconoce que la diversidad y los disensos son fuente de pluralidad política. La 
pluralidad es condición importante para identificar la esencia de la vida pública y es el modo en que la sociedad accede a las fórmulas de acuerdo institucional.

Cuando las oposiciones triunfan se constituyen en elemento importante del gobierno y de los procesos de gobierno. En esa medida, dan cabida a los valores de la institucionalidad para que la democracia continúe siendo un sistema de gobierno fundado en los valores de la tolerancia, la equidad y la civilidad. Las oposiciones con sentido de institucionalidad democrática (Loaeza, 1996a: 53), tienen a su cargo el gobierno de los ciudadanos y la responsabilidad de tomar decisiones para movilizar y aplicar recursos públicos.

Las oposiciones convertidas en gobierno tienen la responsabilidad de que la sociedad se conserve y desarrolle en razón de su valores, principios e instituciones. Pertenecer a la oposición no es sinónimo de conductas vulnerables, de intentos por desestabilizar las instituciones; tampoco implica asumir posturas contrarias a los sistemas de la institucionalidad democrática. Por el contrario, si gobernar implica construir puentes para asegurar los consensos, encauzar los desacuerdos y generar beneficios compartidos, esto significa que la oposición convertida en gobierno debe tener lucidez para dirigir y coordinar en favor de todos. Cuando se gobierna, no deben invocarse los valores partidistas, sino convocar al público ciudadano a participar en las tareas de interés público. Cuando el interés público es el referente del gobierno, se dejan de lado las posturas que tienden a dividir lo que es necesario unir a partir de la diversidad social, política y económica.

De otro modo, lo que se gana en las urnas corre el riesgo de perderse si la cultura partidista le toma la delantera a la cultura institucional. Si esto sucede, el gobierno y la administración pública se politizan innecesariamente, abriendo paso a la ideologización negativa de la función pública y al establecimiento de relaciones clientelares que inciden en el desequilibrio fiscal de los estados, la disminución de la tasa de crecimiento económico y la generación exigua de los beneficios sociales. Erradicar los efectos nocivos de la politización partidista es un imperativo de primer orden para que la función pública no sea botín, prebenda ni patrimonio en favor de intereses privados, corporativos o estamentales. 


\section{Los cambios en el gobierno y la administración pública}

Los procesos políticos del país tienen en la actualidad una dimensión pública de gran importancia. Están permeando la vida de las instituciones y provocan que las mismas revisen sus capacidades de dirección y gestión. En el caso del gobierno y la administración pública, es importante destacar que son instituciones que tienen a su cargo tareas de orden y alcance público. A pesar de circunstancias previstas e imprevistas, su funcionamiento debe garantizarse con plenitud para evitar que se afecte la vida social, política y económica. El desajuste del gobierno y la administración pública debido a la lucha electoral y los triunfos partidistas, provoca inseguridad cuando hay ausencia de procesos que garanticen la continuidad de los programas y las políticas públicas.

Reconocer que en la esfera política suceden cambios importantes que modifican las estructuras y cuotas de poder, significa que el ámbito institucional del gobierno y la administración pública también es influido por las prácticas electorales y partidistas. Por eso, es importante considerar que las elecciones del 6 de julio modificarán en el mediano y largo plazo, el perfil y el funcionamiento de las esferas gubernamental y administrativa.

Si México continúa por la ruta de la democratización del poder, la apertura de los procesos políticos, la confiabilidad de los procesos electorales, los pesos y contrapesos en la médula del régimen político, el énfasis de gobernar a través de políticas públicas y el imperativo de que la función pública sea abierta, tanto las instituciones de gobierno, así como las de carácter administrativo, tendrán que realizar un conjunto de cambios que acrediten con mejores capacidades lo que realizan.

Un cambio previsible en el mundo complejo del gobierno y la administración pública, es la necesidad de profesionalizar el servicio público. Si el juego del poder apunta por una mayor alternancia tanto en los cargos legislativos como en los de la dirección ejecutiva, es importante asegurar la continuidad, el desarrollo y la estabilidad de la función pública. Es fundamental situarla al margen de los vaivenes partidistas, ideológicos y políticos. Es conveniente dotarla de savia institucional para que no se "desarrolle" en las turbulencias de lo que significan la discrecionalidad, la movilidad continua y el final de los periodos sexenales. 
En consecuencia, la profesionalización del servicio público será en los tiempos por venir un cambio estructural que comprende las facetas siguientes: 1) asegurar la lealtad institucional de los servidores públicos; 2) no politizar negativamente las tareas del gobierno y la administración pública; 3) definir y dar vigencia a reglas de certidumbre para asegurar la continuidad de la función pública; 4) formalizar las reglas de un servicio público sustentado en el mérito, la equidad, la continuidad, la seguridad en el cargo y la necesidad de que la función pública tenga como sustento los valores de la ética; 5) reconocer que el ejercicio de la función pública es simultáneo al reconocimiento de la carrera administrativa en sus etapas de formación inicial, reclutamiento, capacitación y desarrollo y sistema de incentivos y 6) fortalecer las tareas de rendición de cuentas y de los procesos de evaluación (Guerrero, 1995: 49). Estos atributos son definitivos para inducir un cambio de fondo en el ejercicio de la función pública.

Sin duda, el cambio institucional es la respuesta para que la acción del gobierno y de la administración pública sean más eficaces. El cambio institucional es una opción para innovar y modernizar la función pública en momentos en que las condiciones del país apuntan por el camino de las transformaciones en todos los órdenes de la vida nacional.

El cambio institucional exige visión para no violentar los principios que conforman la organización del Estado mexicano. Son los principios que han permitido construir las instituciones entre las que destacan el régimen de libertades civiles y públicas, los derechos sociales, la separación de poderes y el reconocimiento de la democracia como un sistema de vida fundado en el mejoramiento constante de la vida económica y social.

El contenido republicano del Estado mexicano se nutre de los principios mencionados y como estructura de poder, se rige no sólo por atribuciones constitucionales y legales, sino también por el reconocimiento de que tiene límites para obrar de acuerdo con la institucionalidad que lo reconoce como centro rector de la sociedad.

En una perspectiva de lo que se desea y lo que se alcanza, la capacidad para emprender el cambio institucional es lo que está a prueba. El modo en que el gobierno y la administración pública sean capaces de institucionalizar los nuevos y los antiguos procesos 
políticos, implica realizar cambios en su modo de funcionamiento. Por ejemplo, atenuar y diluir las prácticas centralistas (Chanes, 1997: 73-74), instituir más relaciones horizontales para comunicarse mejor con la sociedad, mejorar el contenido de las relaciones intergubernamentales, descentralizar el gobierno, modernizar los sistemas de gestión pública e impulsar una mejor y más justa coordinación fiscal entre los distintos órdenes de gobierno (federal, estatal y municipal ).

El cambio del modus operandi en lo que respecta al gobierno y a la administración pública es fundamental para situar el alcance mismo del cambio y las estrategias para inducirlo. Preservar las estructuras que sustentan lo que realizan el gobierno y la administración pública es importante para no afectar los puntos medulares de su funcionamiento.

Gobernar y administrar son tareas que exigen estructuras para dar cauce a la dirección, la coordinación y el desarrollo de la sociedad. En sí, la sociedad es un conjunto de estructuras que se articulan a través de relaciones de intercambio y compromiso. Para sí, la sociedad necesita de un gobierno estructurado que tengan como misión desarrollarla con bases constitucionales, capacidad de gestión pública y aptitud para preservarla con sus expectativas y necesidades.

En consecuencia, dichas estructuras se enlazan con la pervivencia de la sociedad y el Estado. Por eso, su preservación se justifica en razón de lo que sustentan, sin que implique cancelación de oportunidades para impulsar los cambios que son necesarios. La institucionalidad de las estructuras implica el reconocimiento de sistemas, procedimientos, valores e intereses que garantizan la vida en comunidad, de tal modo, que aseguren que los problemas y transformaciones de la sociedad sean absorbidos con funcional eficacia.

Implica reconocer que la institucionalidad gubernamental y administrativa tiene ahora nuevas complejidades. Son complejidades que tienen su origen en la intensidad de la vida social, las cuales se proyectan como una urdimbre de intereses en competencia, que deben abordarse con sapiencia y pragmatismo.

De acuerdo con un planteamiento de cambio institucional, el gobierno y la administración pública tendrán un perfil distinto al actual. Esto significa que deben ser instituciones abiertas, promotoras 
y reguladoras y no como otrora, crecientemente intervencionistas y sobredimensionadas.

Deben ser, por tanto, instituciones que se reencuentran con la sociedad y no incurrir por motivos de "Estado", en un crecimiento inconmensurable de la esfera burocrática y administrativa. Tal situación provoca altos costos fiscales, económicos, sociales y políticos. Son costos que se vierten y revierten negativamente a la sociedad, a sus actividades productivas, a los grupos ciudadanos y limitan el desarrollo futuro de la misma, entendida y organizada como nación que aspira a conseguir la autodeterminación.

\section{La agenda de la investigación}

La nueva realidad política del país representa, desde la visión de las tareas investigativas, una suma de problemas, percepciones y argumentaciones que deben analizarse más allá del sentido común, las obviedades y las prenociones. Es contrario para los fines de la investigación, afirmar que la nueva realidad del país carece de relevancia. Por el contrario, es importante estudiarla, interpretarla y conceptuarla para identificar las relaciones de causalidad que han generado su formación y comportamiento. Esto implica que el gobierno y la administración pública pueden configurarse como un objeto de estudio que tiene caracteres no convencionales, sino que, por su articulación con los procesos de cambio y transformación, ingresan a una etapa de retos y oportunidades que ameritan nuevos estudios y nuevos enfoques de investigación.

Los hechos sociales y políticos no son mecánicos, deterministas ni concluyentes. Son cambiantes, contradictorios y complejos. La nueva realidad de México reúne estas caracterísiticas y los trabajos de investigación tienen que sustentarse a partir de nuevas conjeturas, refutaciones, actores, organizaciones y procesos. Si algo demuestra la realidad entendida como problema, es que su dinámica es producto de relaciones volitivas, intereses en juego, expectativas a cumplir, etapas a recorrer y procesos que impulsan nuevas acciones públicas. En este sentido, hay una veta rica en acontecimientos para analizar y explicar la acción del gobierno y la administración pública.

En México, la realidad del gobierno y la administración pública tienen, entre otros, factores que influirán en su desenvolvimiento funcional y operativo. En este caso, la nueva relación entre el Ejecutivo 
federal y la Cámara de Diputados implicará por parte de ésta lo siguiente: 1) mayor fiscalización de los ingresos y el gasto público; 2) influencia significativa en la composición del gasto público y en su distribución de acuerdo con las prioridades sociales; 3) rendición y justificación oportuna de las cuentas públicas; 4) publicitación, justificación y disminución de las partidas secretas; 5) mayor negociación entre las autoridades hacendarias y financieras con los representantes populares para llevar a cabo la aprobación de la política económica y la correspondiente base presupuestal; 6) trabajo previo para acordar el tipo de legislación a formalizar, así como la aprobación de planes, políticas y programas y sistemas de evaluación; 7) comparecencia no ritualizada de los servidores públicos de primer nivel ante el trabajo de las comisiones legislativas; 8) evaluación y aprobación en conjunto de las acciones gubernamentales y administrativas del nivel federal; 9) negociaciones orientadas a favorecer con más recursos a los gobiernos locales y 10) nuevos reacomodos en la relación del Gobierno federal y los gobiernos locales a partir de las transferencias, la política fiscal y la política del bienestar social.

Con el propósito de identificar las transformaciones institucionales del gobierno y la administración pública en México las cuales se inscriben en un horizonte de más competencia política, es importante considerar como materia de investigación los siguientes elementos: 1) la necesidad de formular una teoría del público para la administración pública mexicana la importancia de profesionalizar la función pública; 2) el imperativo de tener una administración pública emprendedora; 3) la importancia estratégica de que el gobierno tenga capacidad de adaptación; 4) la importancia de que el Congreso cumpla con el quehacer institucional de participar con intensidad en la discusión y aprobación de las políticas públicas; 5) el rediseño del gobierno para que sea más adaptativo; 6) organizar la gobernación del país por redes institucionales; 7) la relevancia del desarrollo institucional; 8) la importancia de que la administración pública recupere su contenido y rostro humanizados y 9) que la reforma de la administración pública, al situarse en el contexto de la reforma del Estado, trascienda el carácter instrumental que es propio de concepciones reduccionistas para situarla como un tipo de cambio institucional. 


\section{Conclusión}

Una ventaja de los sistemas democráticos (Alcántara, 1995: 212) es que permiten el aprendizaje metódico y continuo de las experiencias vividas. El reacomodo democrático que México vive es fuente de información, conductas, valores y objetivos que permite situar la capacidad de los actores políticos para construir y conservar las instituciones democráticas.

A través de las elecciones, la sociedad mexicana ha ingresado a nuevos derroteros de convivencia democrática. Lo importante es que los ciudadanos han optado por la senda de la institucionalidad democrática y en esa medida han de contribuir a que la vida del Estado mexicano sea más pública, abierta y competitiva a nivel del régimen político. Empieza para el país, un capítulo excepcional en cuanto a sucesos y retos. Es un capítulo en el que hay una nueva correlación de fuerzas y por tanto, el sistema de controles democráticos le confiere un perfil más institucional a los procesos de gobierno.

La nueva correlación de fuerzas es innegable. Por tanto, las instituciones públicas tiene ante sí hechos y actores que sintetizan una complejidad inédita. Dicha complejidad es un desafío para quienes detentan el poder y un reto para las fuerzas que han conseguido alterar y modificar con el voto ciudadano, el conservadurismo del sistema político mexicano.

Sin duda, el sistema político mexicano se encuentra en transición y los reajustes que en él se dan, provocan que las estructuras de gobierno y los procesos de la administración pública tengan que ser objeto de adaptación inteligente para que continúen como pilares de la vida pública. En efecto, la adaptación inteligente es exigida por los nuevos contrapesos institucionales, por el auge de las energías ciudadanas, por los reclamos para que continúe la democratización del poder y por el propósito de que los valores, procedimientos, controles y logros de la democracia se institucionalicen como un sistema de vida deseado y esperado.

\section{Bibliografía}

Aguilar Villanueva, Luis F. (1996), "La silenciosa, heterodoxa reforma de la administración pública", en Revista de Administración Pública, núm. 91, México: Instituto Nacional de Administración Pública. 
Alcántara Sáenz, Manuel (1995), Gobernabilidad, crisis y cambio, México: Fondo de Cultura Económica.

Arbós, Xavier y Salvador Giner (1996), Ciudadanía y democracia en la encrucijada mundial, Madrid: Editorial Siglo XXI.

Bell, Daniel (1996), Las contradicciones culturales del capitalismo, México: Alianza Editorial.

Bobbio, Norberto (1996), El futuro de la democracia, México: Fondo de Cultura Económica.

Chanes Nieto, José (1997), Administración política, México: Universidad de Guanajuato, Facultad de Derecho.

Elizondo Mayer-Serra, Carlos (1997), "Impuestos y democracia", en Enfoque Reforma, núm. 203, noviembre.

Fernández Santillán, José (1997), Liberalismo democrático, México: Editorial Océano.

Guerrero Amparán, Juan Pablo (1885), "La evaluación de políticas públicas: enfoques teóricos y realidades en nueve países desarrollados", en Revista de Gestión y Política Pública, vol. IV, núm. 1, México: Centro de Investigación y Docencia Económicas.

Loaeza, Soledad (1996), "Liberalización política e incertidumbre en México", en Las dimensiones políticas de la reestructuración económica, México: Editorial Cal y Arena.

(1996a), "Oposición y democracia", en Cuadernos de Divulgación de la Cultura Democrática, núm. 11, México: Instituto Federal Electoral.

Marván Laborde, Ignacio (1997), “¿Y después del presidencialismo?”, en Reflexiones para la formación de un nuevo régimen, México: Editorial Océano.

O’Donell, Guillermo (1996), "Otra institucionalización”, en Revista Política y Gobierno, vol. III, núm. 2, México: Centro de Investigación y Docencia Económicas.

Peschard, Jacqueline (1996), "La cultura política democrática", en Cuadernos de Divulgación de la Cultura Democrática, núm. 2, México: Instituto Federal Electoral.

Przeworski, Adam (1991), "Democracy and the market", en Political and Economic Reform in Eastern Europe and Latin America, Inglaterra: Cambridge University, Press.

(1997), "Las condiciones para la sobrevivencia de la democracia", en Política y Ciencia Política, Conferencias Magistrales del Congreso Nacional de Ciencia Política.

Rawls, John (1996), Liberalismo político, México: Fono de Cultura Económica.

Ruiz Massieu, José Francisco (1994), El proceso democrático de México, México: Fondo de Cultura Económica.

Silva-Herzog, Jesús J. (1996), "Esferas de la democracia”, en Cuadernos de Divulgación de la Cultura Democrática, núm. 9, México: Instituto Federal Electoral. 